filters and slowly injected into the thorax. (As the air expands when heated to body temperature by 10 per cent. of its volume, $45 \mathrm{c} . \mathrm{cm}$. are used to replace $50 \mathrm{c.cm}$.) When this has been done a few times the presence of a gas bubble can be made out by percussion in the upper part of the chest anteriorly. The skin and pleura are again anaesthetized over this, and a trocar connected with a water manometer is passed into it. The presence of the gas bubble prevents injury to the lung, and, as a rule, makes the entry no more difficult than a simple refill. The pressure is read and aspiration and air filling continued as before, until the chest is dry, keeping the pressure in the manometer at a constant figure.

It will be found that much less air than fluid is required to maintain this pressure, because of the expansion of the gas and the rising of the diaphragm when it is freed from the weight of the fluid. For this reason also it is not desirable to insert the aspirating trocar too low in the pleural sac, as the ascending diaphragm may obstruct it. The difficulties are few. A " dry tap" may occasionally be met with. This results from entering a band of adhesion or organizing tissue in the base. These are comparatively common in effusions that have stood for a long time. Pleural shock is prevented by careful anaesthetizing, and all pain, discomfort, and distress by replacing the fluid by gas as it is removed. There is no danger from cough, faintness, or oedema of the lung. Gas embolism is prevented by careful preliminary aspiration and the avoidance of a high positive pressure in the thorax.

This method entails the insertion of a second needle in the upper part of the chest, the advantage of which is that the intrapleural pressure may be watched and kept constant all through the operation.

A much simpler procedure may be carried out with one aspirating trocar only, replacing the fluid with two-thirds of its volume of air. When the chest is quite empty of fluid, and only the replacement air is being sucked through the syringe, the latter is half rotated-which seals off the chest-whilst a manometer is connected by a simple adapter to the end of the trocar, and the tap turned to put it into communication with the pleural cavity. The pressure is read, and if positive is adjusted by slow removal of air until a pressure between 0 and -4 is obtained. This method reduces gas replacement to its simplest term. It is entirely a single-handed procedure, and is within the capabilities of everyone who can use a syringe and has the minimum degree of manual dexterity.

If for any purpose it is desirable to employ oxygen, a rubber bag containing the gas can be attached to the air filter.

\section{PURULENT EFFUSIONS}

Tuberculous purulent effusions may be treated by gas replacement, oleothorax or gelatinothorax, or early thoracoplasty.

The rotanda syringe method is ideal for making an oleothorax. The chest is emptied of pus, which is replaced by oxygen ; with the patient lying on the sound side the procedure is, reversed. The oxygen is aspirated and the oil slowly injected.

Lastly, in certain cases of pneumococcal or streptococcal empyemas, total aspiration and oxygen replacement offers a very simple and adequate treatment. In these cases oxygen is used to promote expansion of the lung by its more rapid absorption, and a negative pressure as high as can be comfortably borne is maintained for the same purpose. The absence of any external opening is an immense advantage. Finally, the chest may be washed out and an effusion thinned by repeatedly pumping in and out Dakin's solution or any other antiseptic fluid.

\section{CONCLUSIONS}

1. Pleural effusions are essentially dangerous.

2. Current treatment adds to, rather than diminishes, these dangers.

3. A really satisf-ctory method of treatment does exist.

4. It has failed to achieve popularity through wrong approach to the problem and through difficulties of technique.

5. A method of overcoming these difficulties is described.

REFERENCES

${ }^{1}$ Burrell, L. S. T.: Modern Technique in Treatment, vol.iv, p. 208 ; British Medical Journal, April 11th, 1931, p. 620.

2 Norris and Landis: Diseases of the Chest, fourth edition, p. 646

3 Parker, R. W.: Lancet, 1882, i, 689 .

"Potain: Bull. de l'Académie de Méd., 1888, Second Series, xix, 537. ${ }_{5}$ Potain: Bull. de l'Académie de Méd., 1888, Second Series, xix, 537.
Burrell, L. S. T.: British Medical Journal, loc. cit.; Recent Advances in Pulmonary Tuberculosis, Churchill, 1929, p. 70.

\section{THE MEAN TEMPERATURE OF HEALTHY GIRLS}

BY

J. H. P. PATON, M.D.

MEMIBER OF THE STAFF OF THE JAMIES MIACKENZIE INSTITUTE FOR CLINICAL RESEARCH

In the Journal of May 28th, 1932, Lyon and Wallace ${ }^{1}$ point out that the temperature of afebrile hospital patients as recorded night and morning is slightly more than $1^{\circ}$ below the "normal" temperature reading $\left(98.4^{\circ} \mathrm{F}\right.$.). They state that " it is not unreasonable to assume, therefore, that if the temperature of a recumbent individual suddenly rises from $97^{\circ}$ to $98.4^{\circ} \mathrm{F}$. that individual is also slightly febrile, despite the fact that the temperature has not risen above the conventional limit."

\section{Details of Investigation}

The following observations, made in a large boarding school for girls, suggest that these conclusions are also true of healthy girls engaged in active life.

The information which I have to submit was obtained exclusively from records of girls of from 14 to 17 years of age. This limitation must be made perfectly clear because it may be injudicious to assume that the results are applicable to persons of different age or of the opposite sex. It is known, for example, that the temperature and pulse of younger children are less stable than those of older children, and it is possible that girls of 14 to 17 may differ in some degree from adults or from boys.

It is commonly assumed, for example, that the temperature of convalescents is usually subnormal. In the majority of cases, however, the convalescent reading is of the same order as that found in health as illustrated in Charts 1 and 2.

In both, the convalescent temperature is almost uniformly below $98^{\circ}$, and might therefore be considered subnormal but for the fact that it differs in no way from the reading obtained from the same individuals in health.

In particular, the so-called normal temperature $\left(98.4^{\circ} \mathrm{F}\right.$. or, according to some authors, $98.6^{\circ} \mathrm{F}$.) is so rare that, in my experience, its occurrence in adolescent girls always warrants a strong suspicion of ill-health.

On three occasions, for a continuous period of about a fortnight, a record was kept of the morning and evening temperatures of a group of healthy girls leading an active school life. The temperatures were all taken orally with thermometers certified by the National Physical Laboratory. Two precautions were observed throughoutnamely, that the records should not be taken $(a)$ within half an hour after meals, or $(b)$ within an hour of participation in an active game. Altogether 108 girls were 
observed morning and evening, and 3,655 temperature readings were recorded.

0.06 per cent. of these reached $99^{\circ} \mathrm{F}$. or over.

6.6 per cent. were between $98.4^{\circ}$ and $99^{\circ} \mathrm{F}$.

$17.9^{2}$ per cent. were between $98^{\circ}$ and $98.4^{\circ} \mathrm{F}$.

39.8 per cent. were between $97^{\circ}$ and $98^{\circ} \mathrm{F}$.

34.9 per cent. were below $97^{\circ} \mathrm{F}$.

That is to say, only one-quarter of the readings were above $98^{\circ} \mathrm{F}$., and no less than 75 per cent. of the readings obtained were "subnormal" according to the standard just quoted.

\section{Convalescence and Health}

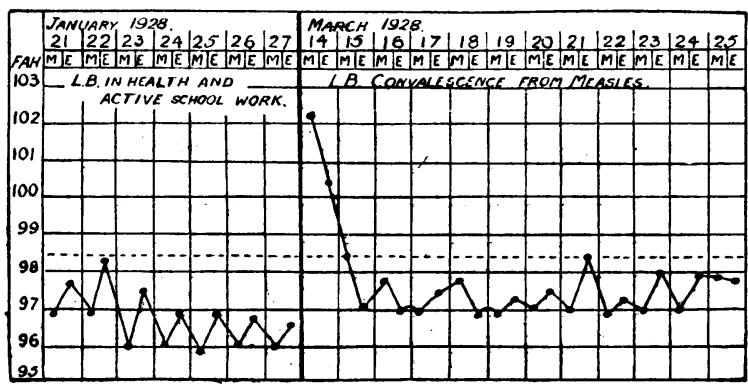

Chart 1

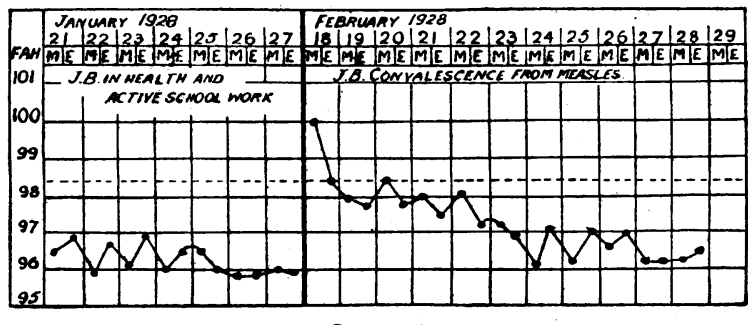

Chart 2

\section{Analysis of Results}

There are reasons for assuming that even these results do not place the normal or ruling temperature sufficiently low.

1. In the first group of girls examined $(2,177$ observations upon sixty-one girls) the records above $98^{\circ} \mathrm{F}$. were about 10 per cent. more frequent than in the two later groups. At the time when these first observations were made there was a week of unusually heavy frost. In the evenings, on returning from games or skating, there was a strong inducement for the girls to congregate round hot fires in warm rooms. That this resulted in some increase in the general level of the temperatures recorded seems probable from the fact that on the coldest night of all more than half of the girls in one house were reported to me as showing temperatures of $98.4^{\circ} \mathrm{F}$. or over. On inquiry they all admitted that they had been sitting round the fire in a very hot room. This source of probable error was avoided in the later series.

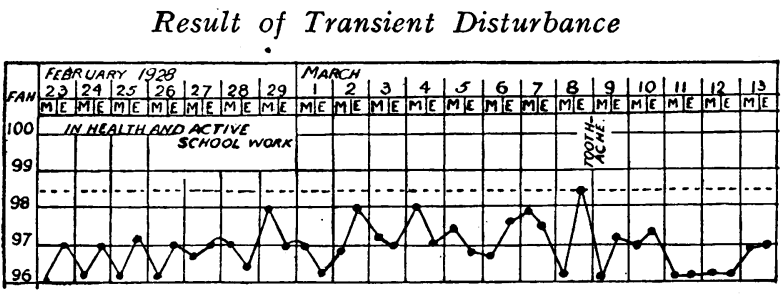

ChaRT 3

2. It is probable that many of the occasional readings of $98.4^{\circ} \mathrm{F}$. or over were due to some transient disturbance of health, as is instanced by Chart 3 .
3. A few individuals have an habitually high level of temperature. Chart 4 is taken from a girl in the first group who showed the highest average in this respect.

Persistent High Level

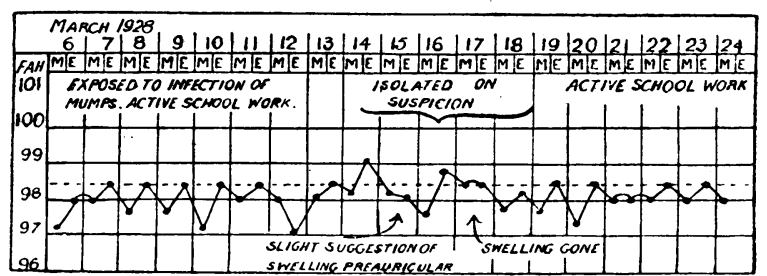

Chart 4

But even in her case it is evident that $98.4^{\circ}$ was reached in less than half of the readings. Such an individual record raises the average.

Chart 5 is the record of the captain of games, whose activity is undoubted.

Active Type

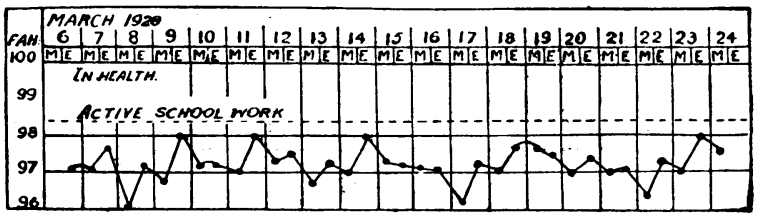

Charr 5

The following conclusions may, I think, be safely drawn from these figures :

1. The normal (or ruling) temperature of girls of from 14 to 17 years of age is nearer $97.4^{\circ}$ than $98.4^{\circ}$.

2. Girls in whom the mean approximates to $98.4^{\circ}$ are very rare.

3. A temperature of $98.4^{\circ}$ in the mouth is so suggestive of illness that it should not be disregarded unless no other disturbance of health can be detected.

\section{Clinical Application in Exanthemata}

The clinical importance of these conclusions from the point of view of the early detection and prevention of the exanthemata and other infective diseases is undoubted, because, in most of these diseases, a departure from the patient's usual range of temperature can be detected before characteristic symptoms appear, and, what is of greater moment, before the patient has become infectious to others. This is well illustrated in measles. It is known

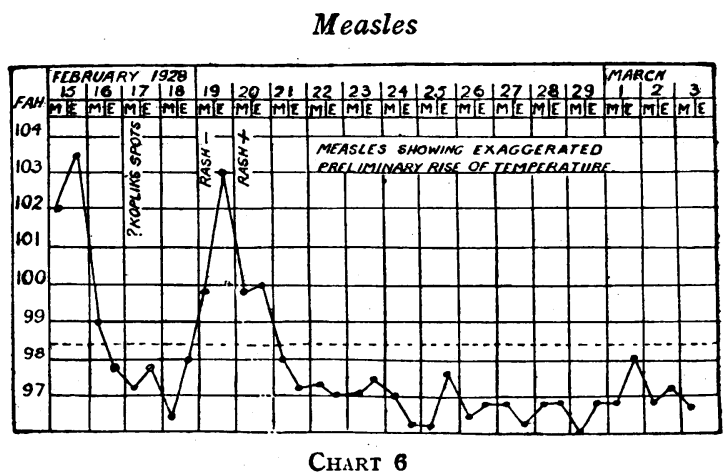

that in most cases of measles there is a preliminary rise of temperature four or five days before the full developinent of the disease, and that this brief rise is often succeeded by a period of twenty-four to forty-eight hours during which no febrile disturbance is evident (Chart 6). 
Claud Ker makes the following statement in this connexion: "It may be noted that occasionally there is practically no pyrexia in the invasion stage, although sometimes the axillary temperature of a child, hitherto steadily subnormal; may give useful warning by rising to the normal level." I can fully corroborate this, but I believe $I$ am justified in taking the matter further, and in saying that if the temperature is recorded throughout the incubation period a rise above the patient's previous level will give this warning in almost every case. Charts 7, 8, and 9 illustrate this preliminary rise.

\section{Preliminary Rise in Measles}

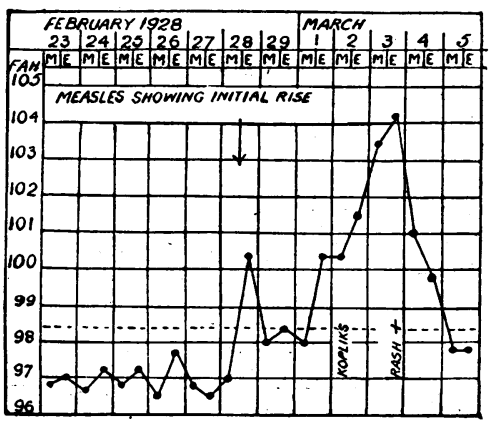

Chart 7
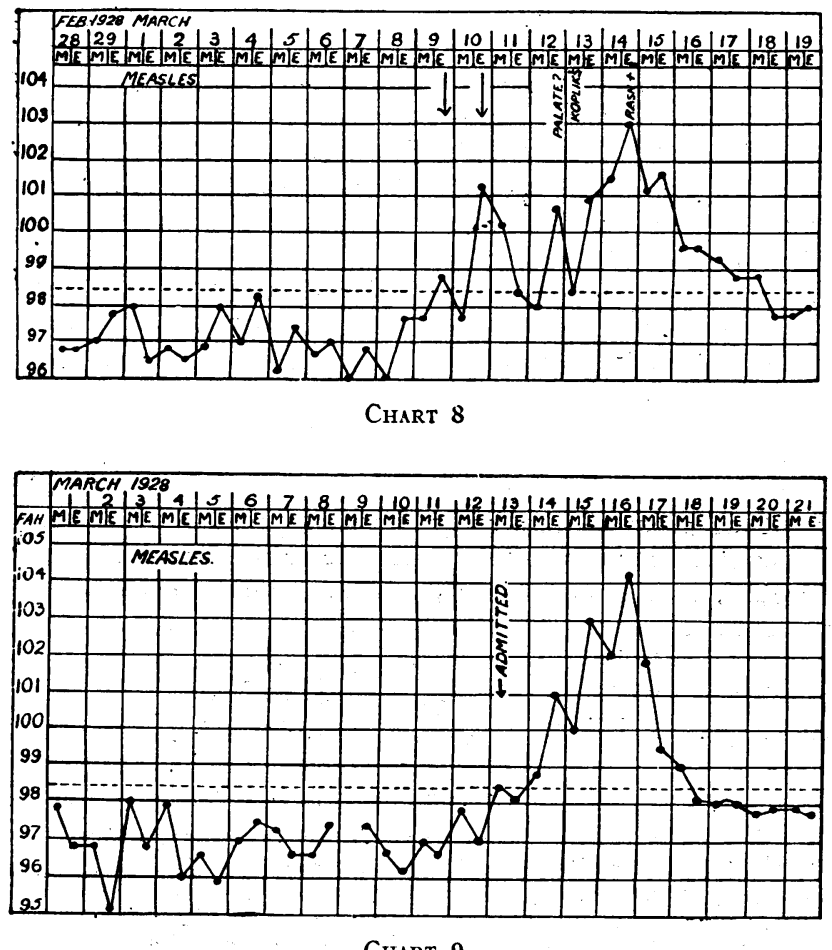

Chart 9

In two of them the rise is obviously febrile, while in the third its pathological significance only becomes evident by comparison with the previous readings.

In view of the fact that the textbook teaching considers $98^{\circ}$ to $99^{\circ}$ a normal temperature, and that manufacturers of charts and thermometers stereotype the figure $98.4^{\circ}$ as normal, I find it difficult to convince everyone that such a temperature warrants isolation of a susceptible measles contact. In a recent outbreak, measles escaped from control for this very reason, and eighty cases resulted.

Two of the offending charts are reproduced (Charts 10 and 11).
Typical Charts in an Outbreak

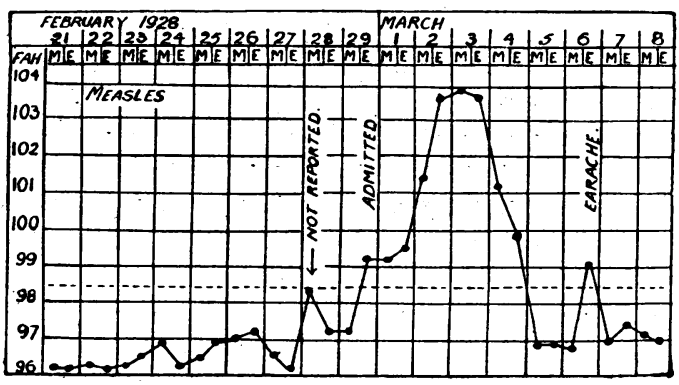

Charr 10

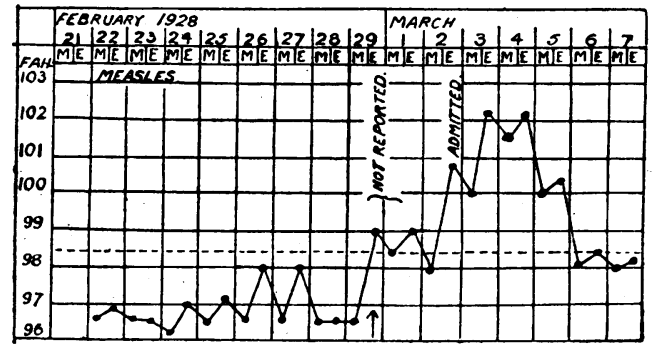

CharT 11

Once it is realized that the traditional figure of $98.4^{\circ} \mathrm{F}$. is misleading, and that this preliminary rise can be detected by comparison with the previous temperature, an important step is taken in the prevention of measles-one of the most anxious and dangerous diseases when it occurs in the form of an uncontrolled epidemic.

The following example illustrates the advantage of this interpretation of the temperature chart. In the spring of 1924 forty girls were isolated during the first fortnight of the term (the period during which exanthemata which have been contracted during the holidays developed) because of a rise of temperature to $98.4^{\circ} \mathrm{F}$. Ten or fifteen of these were in every respect normal on the following day and were permitted to return to school. Twenty were found to be suffering from feverish colds and were kept out of school until well. Four developed measles. There were thus four potential sources of an epidemic. But as a result of the prompt isolation secured by the reporting of temperatures of $98.4^{\circ} \mathrm{F}$. no other case of the disease appeared during the term.

These results demonstrate the frequent pathological significance of a temperature of $98.4^{\circ} \mathrm{F}$. in the mouth and the serious consequences which may follow from the belief that temperatures between $98^{\circ}$ and $99^{\circ}$ are normal or that a temperature of $98.4^{\circ}$ is evidence of health and may be disregarded.

\section{CONCLUSIONS}

1. A temperature of $98.4^{\circ}$ in a girl of from 14 to 17 years of age is, as a rule, the result of pathological disturbance, and this is certain if it is accompanied by increase in the rate of the pulse or by disappearance of the normal respiratory irregularity. ${ }^{2}$

2. The absence of sinus arrhythmia is of value in recognizing the presence of disease, and its return in convalescence affords a useful guide as to the advisability of fermitting the patient to get up.

\section{REFERENCES}

Lyon, D, M., and Wallace, H. L.: "The Mean Temperature in Non-febrile Hospital Patients," British Medical Journal, May 28 th, 1932, p. 980 .

2 Paton: "Cardiac Arrhythmia in Childhood," Edin. Med. Journ. January, 1927. 